\title{
California's rice crop: market challenges, resource constraints
}

\author{
Elmer W. Learn
}

\begin{abstract}
California's rice industry faces numerous challenges as it strives to meet competitive pressures in the coming decade. In addition to traditional demand considerations population and income growth, and changing consumer tastes - competitiveness will be affected by future trade regulations and price support policies. On the supply side, adjustments to current and potential environmental regulations affecting the use of land and water are likely to be of greatest importance to California producers.
\end{abstract}

California's rice industry needs to maintain and expand both its domestic and foreign markets. The substantial increases in per-capita consumption of rice within the United States during the 1980s continue upward, but possibly at a slower rate, and California can expect to share this expanding domestic market with Southern U.S. rice-producing states. International trade typically accounts for only 3 to $4 \%$ of the world's total rice production as almost all rice is consumed within the country where it is grown. In the U.S., however, about half of the rice production is exported. The U.S. accounts for about $20 \%$ of total world trade in rice, ranking only behind Thailand which has about $40 \%$ of the total.

Less than one-third of California's rice production is sold abroad, but its future abroad holds promise because California's rice is the type (japonica) demanded by nations such as Japan and Korea. However, that promise is conditioned by the degree to which Japan and Korea can be encouraged to reduce the extreme quantitative restrictions currently imposed on imported rice.

In addition to seeking markets, California rice growers face issues related to air and water quality, sharing multiple-use

At left: Harvesters reap Sutter County rice. California's industry faces a growing market here and abroad: American per-capita rice consumption has increased approximately $100 \%$ since 1970 . In addition, California's japonica rice is the type demanded by nations such as Japan and Korea. wetlands, and competing with urban and other agricultural users for water.

Furthermore, during the next 20 years, California's rice industry will see potential changes in domestic farm programs and related trade regulations.

\section{Demand}

Most rice grown in the world today belongs to one of two classes: indica and japonica. Indica is the most common, a family of long-grain varieties grown primarily in tropical and subtropical regions. Indica varieties predominate in Arkansas, Texas and other southern rice-producing states. California mostly grows japonica, a temperate-zone family of mainly medium and short-grain varieties usually grown in Japan, Korea, northern China, Taiwan and, on a smaller scale, in Australia and Europe.

Rice consumers in the U.S. and elsewhere show only limited preference for one class of rice over the other. But, in nations where rice is a staple, the two classes can be seen as almost distinctly separate commodities. (Consumers are loyal to one class and very large price differences are required to effect any meaningful substitution.) Thus, Japan and Korea's trade policies are of special import to California's rice industry.

Although rice has never attained the status of a staple in American diets, percapita consumption has increased approximately $100 \%$ since 1970 to a level of 21 pounds per year (compared with Japan's 150 pounds or Indonesia's 320). This upward trend in U.S. consumption, attributable to nutritional considerations, recent immigration patterns, and a desire for more variety in the diet, may continue - but probably not at the same rate. Many other foods have nutritional benefits similar to those recently identified with rice (for example, its ability to reduce cholesterol) and the influence of immigration may slacken as recent arrivals adopt U.S. eating habits. Nevertheless, even a modest per-capita increase, combined with a projected $10 \%$ increase in population, could substantially increase total domestic demand for rice.

Because domestic consumers exhibit only limited preference between japonica

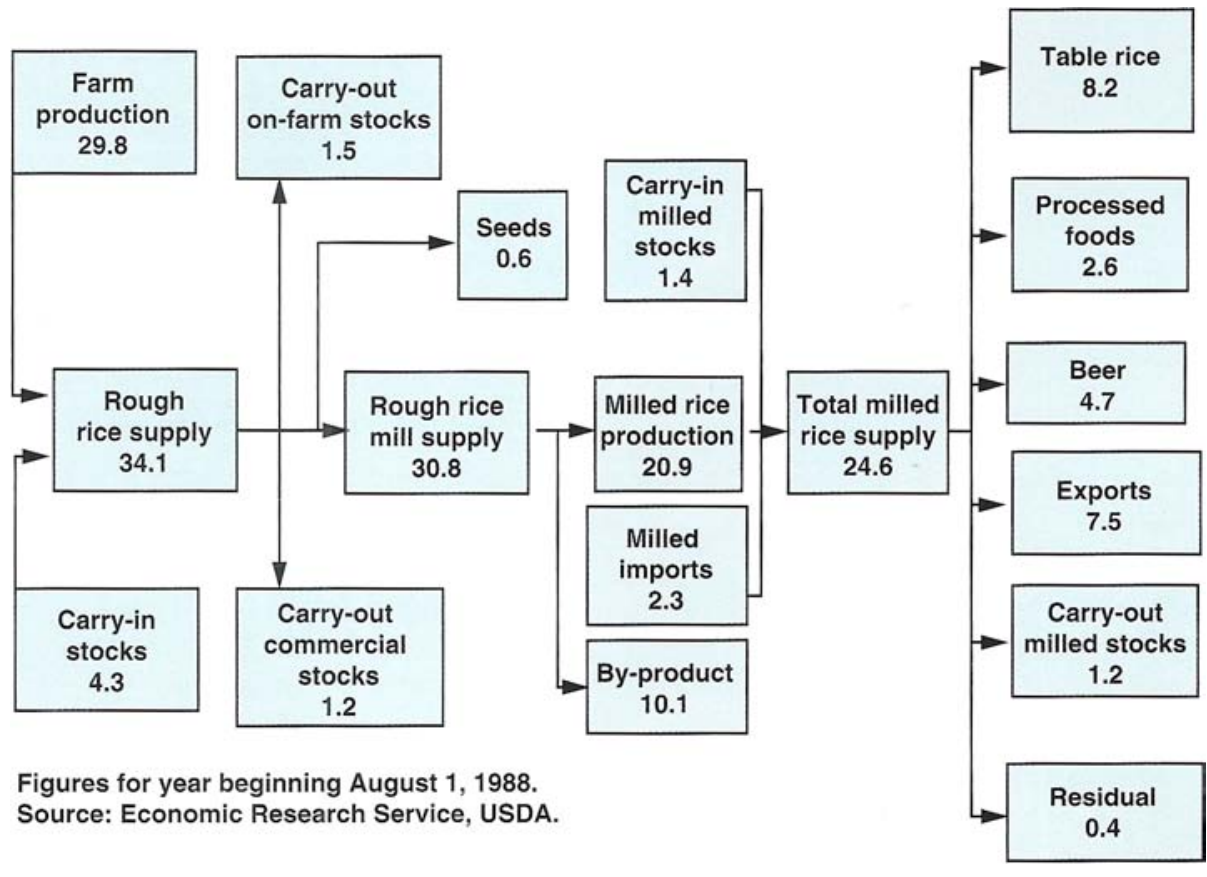

Fig. 1. Market channels for California rice with estimated flows for 1988-1989, a normal year that reflects operation of federal price support programs. Units are million-cwt., rough basis, except where indicated as milled basis. 


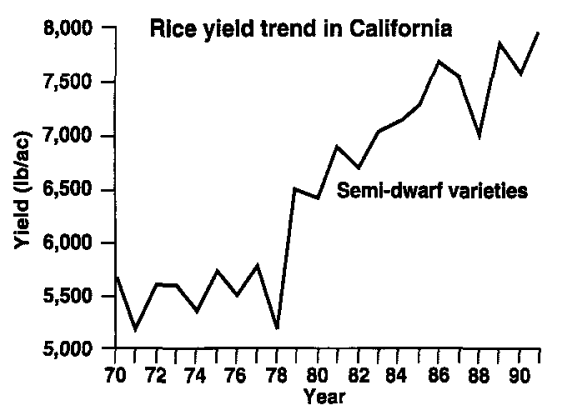

Source: Callfornia Field Crop Stat/stics, various years.

Fig. 2. Yields of semi-dwarf japonica rice varieties grown in California have increased from less than 6,000 pounds per acre in 1970 to more than 8,000 pounds in 1991. and indica varieties, costs related to transportation and processing take on added importance for California producers who must compete with counterparts in the Arkansas/Texas region for the domestic market. These costs largely limit the competitiveness of California rice for table use to areas west of the Rocky mountains. This is offset, partly, by the disproportionately large use of California rice in breakfast cereals and other processed foods, and in the brewing industry. California's share of rice sold in the United States for processed foods and brewing is almost $40 \%$, about double the state's share of production. However, this market is less desirable because the amount used for brewing varies greatly from year to year and much of the rice for both brewing and processing con-

\begin{tabular}{|c|c|c|c|c|c|c|c|c|}
\hline County & $\begin{array}{c}1975 \\
\text { Acres } \\
\text { harvested }\end{array}$ & Yield & $\begin{array}{c}1980 \\
\text { Acres } \\
\text { harvested }\end{array}$ & Yield & $\begin{array}{c}1985 \\
\text { Acres } \\
\text { harvested }\end{array}$ & Yield & $\begin{array}{c}1990 \\
\text { Acres } \\
\text { harvested }\end{array}$ & Yield \\
\hline & & $\mathrm{lb} / \mathrm{ac}$ & & $\mathrm{lb} / \mathrm{ac}$ & & $\mathrm{Ib} / \mathrm{ac}$ & & $\mathrm{lb} / \mathrm{ac}$ \\
\hline \multicolumn{9}{|c|}{ Sacramento Valley } \\
\hline Butte & 91,900 & 5,600 & 104,000 & 6,550 & 72,000 & 7,410 & 58,750 & 7,900 \\
\hline Colusa & 127,500 & 6,000 & 138,000 & 6,560 & 98,000 & 7,300 & 88,800 & 7,400 \\
\hline Glenn & 65,100 & 6,100 & 77,000 & 6,750 & 61,000 & 7,350 & 62,900 & 7,500 \\
\hline Placer & 6,800 & 5,300 & 10,000 & 6,200 & 10,500 & 7,100 & 12,200 & 7,900 \\
\hline Sacramento & 14,200 & 5,500 & 18,000 & 6,100 & 11,000 & 7,790 & 9,600 & 7,800 \\
\hline Sutter & 98,700 & 5,900 & 98,000 & 6,600 & 65,000 & 7,460 & 69,600 & 7,600 \\
\hline Tehama & 500 & 5,600 & 200 & 6,000 & 2,000 & 6,500 & 1,300 & 6,000 \\
\hline Yolo & 35,700 & 5,800 & 36,000 & 6,300 & 25,500 & 6,940 & 25,000 & 7,760 \\
\hline Yuba & 24,200 & 5,800 & 34,000 & 6,400 & 23,000 & 7,300 & 27,900 & 8,380 \\
\hline \multicolumn{9}{|c|}{ San Joaquin Valley } \\
\hline Fresno & 22,600 & 5,000 & 11,000 & 5,600 & 6,400 & 6,170 & 6,200 & 6,380 \\
\hline Kern & 8,400 & 4,900 & 4,500 & 4,000 & 800 & 6,750 & 600 & 6,340 \\
\hline Kings & 1,000 & 4,900 & 4,000 & 5,000 & & & & \\
\hline Madera & 500 & 4,400 & 400 & 6,000 & & & & \\
\hline Merced & 12,100 & 5,800 & 12,000 & 6,200 & 8,400 & 7,640 & 5,300 & 7,440 \\
\hline San Joaquin & 10,500 & 5,700 & 8,000 & 6,000 & 4,900 & 6,630 & 4,950 & 8,000 \\
\hline Stanislaus & 3,200 & 5,400 & 4,700 & 5,790 & 2,600 & 6,850 & 2,430 & 7,440 \\
\hline Tulare & 2,100 & 4,800 & 5,200 & 5,100 & & & & \\
\hline Total & 525,000 & 5,800 & 565,000 & 6,440 & 390,000 & 7,300 & 385,000 & 7,600 \\
\hline
\end{tabular}

${ }^{\star}$ Paddy rice at $13 \%$ moisture.

Source: California Department of Food and Agriculture, California Field Crop Statistics.

TABLE 2. Summary of cost of production, drying, trucking and milling rice by grain type and state (milled basis)

\begin{tabular}{|c|c|c|c|c|c|}
\hline Grain type & Arkansas & California & Delta & Louisiana & Texas \\
\hline & $\ldots$ & . & milled & (n............ & ................ \\
\hline \multicolumn{6}{|l|}{ Long grain } \\
\hline Production & 14.08 & 15.02 & 14.55 & 15.55 & 14.13 \\
\hline Dry, store, truck, mill & 5.21 & 6.60 & 5.84 & 5.69 & 5.97 \\
\hline Total & 19.29 & 21.62 & 20.39 & 21.24 & 20.10 \\
\hline \multicolumn{6}{|l|}{ Medium grain } \\
\hline Production & 13.49 & 13.47 & 13.94 & 14.90 & 13.54 \\
\hline Dry, store, truck, mill & 4.63 & 5.65 & 5.22 & 5.08 & 5.32 \\
\hline Total & 18.12 & 19.12 & 19.16 & 19.98 & 18.86 \\
\hline \multicolumn{6}{|l|}{ Short grain } \\
\hline Production & 13.07 & 15.80 & 13.50 & 0 & 0 \\
\hline Dry, store, truck, mill & 4.24 & 5.90 & 4.80 & 0 & 0 \\
\hline Total & 17.31 & 21.90 & 18.30 & 0 & 0 \\
\hline
\end{tabular}

Sources: Wailes and Holder, University of Arkansas; Economic Research Service, USDA.

sists of lower-valued broken grains rather than whole-grain ("head") rice (fig. 1).

Demand for rice internationally is limited because most major rice-consuming nations are self sufficient. Unless their domestic agricultural and trade policies change, there is little potential for increased U.S. exports of rice, especially for japonica varieties. In the largest potential rice import market, Japan, growers have so far successfully fended off efforts to relax prohibitive import restrictions.

\section{Supply considerations}

Rice acreage in California has fluctuated from 600,000 acres in the early 1980 s - an unusual circumstance resulting from purchases by South Korea - to less than 320,000 acres in 1991, a drought year. Since 1985, acreage has been determined largely by acreage restrictions imposed under federal price support programs.

Rice yields, on the other hand, have increased sharply since 1980 due, largely, to introduction of semi-dwarf varieties. Yields in California, which averaged 80 cwt/acre in 1991, have been a primary source of California's competitive strength. California's high yields result from a combination of favorable climate, tailored varieties and intensive farming. Whether this advantage is maintained will depend on how well farmers adapt to limitations on water supplies and increasing regulations related to air and water pollution, fish and wildlife, and other environmental concerns (table 1 and figure 2).

Today, California's costs for milling, storing and transportation are somewhat higher than in the rest of the United States. Much of the difference relates to postharvest storing and processing due, partly, to lower yields of whole grain ("head") milled rice from unprocessed (paddy) rice. These costs are compounded by higher transportation costs incurred by California producers, compared with those from Arkansas or Texas, in shipping to eastern population centers. California's location on the Pacific Rim, however, gives it a distinct advantage in East Asia's large potential markets (table 2).

\section{Rice and natural resources}

Because of its unique need for soil with high water-holding capacity, rice provides economic value to acreage with little other agricultural use. Furthermore, rice fields contribute to the environmental value of large open spaces and provide feeding areas for enormous numbers of waterfowl. On the other hand, rice cultivation practices can degrade air and water quality, and rice irrigation competes for a scarce water supply. Attempts to achieve compromise solutions to these complex re- 
source issues will strongly influence the future of California's rice industry.

Air quality. The burning of approximately 3 tons of rice straw for every acre of rice harvested contributes to atmospheric pollution, an issue that has created increasing public concern since the 1950s. Recent legislation (AB 1378, 1991) launched a "phase down" program; burning will be reduced by $10 \%$ annually until 1998. After that, a maximum of $25 \%$ of the planted acreage (or 125,000 acres, whichever is less) could be burned - but only under special permits.

A central question for the industry, therefore, is: What are the alternatives to burning, and how will they affect the competitiveness of California rice? An economically viable alternative for disposing of all or most rice straw in California is badly needed. Alternatives - none fully satisfactory and all probably more expensive than burning - include: (1) rotating crops, which reduces the likelihood of crop damage and income loss due to disease carried in the rice stubble, (2) incorporating the residue into the soil, and (3) hauling it out of the field. (Some have suggested rice straw be put to nonagricultural use, for example as biomass fuel; however, hauling expense makes the latter prohibitive.) Analyses of the benefits and costs associated with each alternative are presented in the Agricultural Issues Center publication

Water quantity and quality. Historically, virtually all rice was irrigated with surface water from the Sacramento River and was often reused several times. During the current drought - and perhaps increasingly in the future - pumped groundwater, although much more costly, has been used to supplement surface supplies. The minimum amount of water required to grow a crop of rice - that used by the crop through evapotranspiration is about 42 inches, which is not much greater than that required for other longgrowing season field crops, such as alfalfa. However, unavoidable losses due to percolation and tailwater outflows add to this amount so that the amount of water diverted varies from 50 to as much as 100 inches per acre (4.2 and 8.4 acre-feet). As water becomes scarce and/or more expensive, soils with high percolation rates may well be shifted to other crops. In addition, adoption of new irrigation systems will reduce water losses at the lower end of the field. These systems have important implications for the quality of both water and soil.

For the past 10 years, California's rice industry has been the focus of an intensive regulatory and educational program to reduce water pollution caused by pesticides. The principal conclusion, described in de- tail in the AIC publication, is that rice grower management has reduced pesticide discharges so much that all current water quality objectives - for herbicides, at least - eventually will be met. But this will not end water quality problems. Future programs dealing with release of nutrients and other constituents of rice field drainage into surrounding rivers and streams may be required. New types of irrigation systems, referred to above, that reduce or eliminate drainage by recycling rice-irrigation water on the farm may help solve many of these problems.

\section{Government's role}

Markets for rice are universally influenced by government policies on commodity price and income supports, consumer subsidies, and trade subsidies and restrictions. It is virtually impossible to predict what will occur if widespread calls for reducing governmental influence are heeded. As suggested earlier, of greatest importance to California rice growers is the possible major modification of U.S. policies and an accompanying relaxation of Japanese and other nations' import restrictions resulting from the multi-lateral trade negotiations now being conducted under the General Agreement on Tariffs and Trade.

Because Japan's consumption is so large (more than 7 times that of the U.S. on a per-capita basis), even a modest relaxation of import restrictions there could significantly increase California's exports. For example, California's recent yearly production of rice would satisfy only about $10 \%$ of Japan's annual consumption. This would be reasonably certain in the short run because of California's capacity to produce the type of rice the Japanese prefer. It is possible, however, that the attraction of a huge Japanese market and favorable prices (favorable at least for japonica compared with indica varieties) could increase efforts of other nations to develop a japonica variety suited to their growing conditions. Or, it may be that, given free access to world markets and a substantial price differential between indica and japonica varieties, Japanese consumers might become less averse to the more plentiful indica rice. Furthermore, as incomes rise, it seems certain that some of the world's most important rice consumers may follow the Japanese trend of reducing per-capita consumption of rice to achieve greater variety in their diets.

In any event, it seems certain that, even if freer trade becomes a reality, competition within domestic and international markets will be an ongoing issue for California's rice industry. Maintaining California's reputation for high quality rice while reducing production, process-

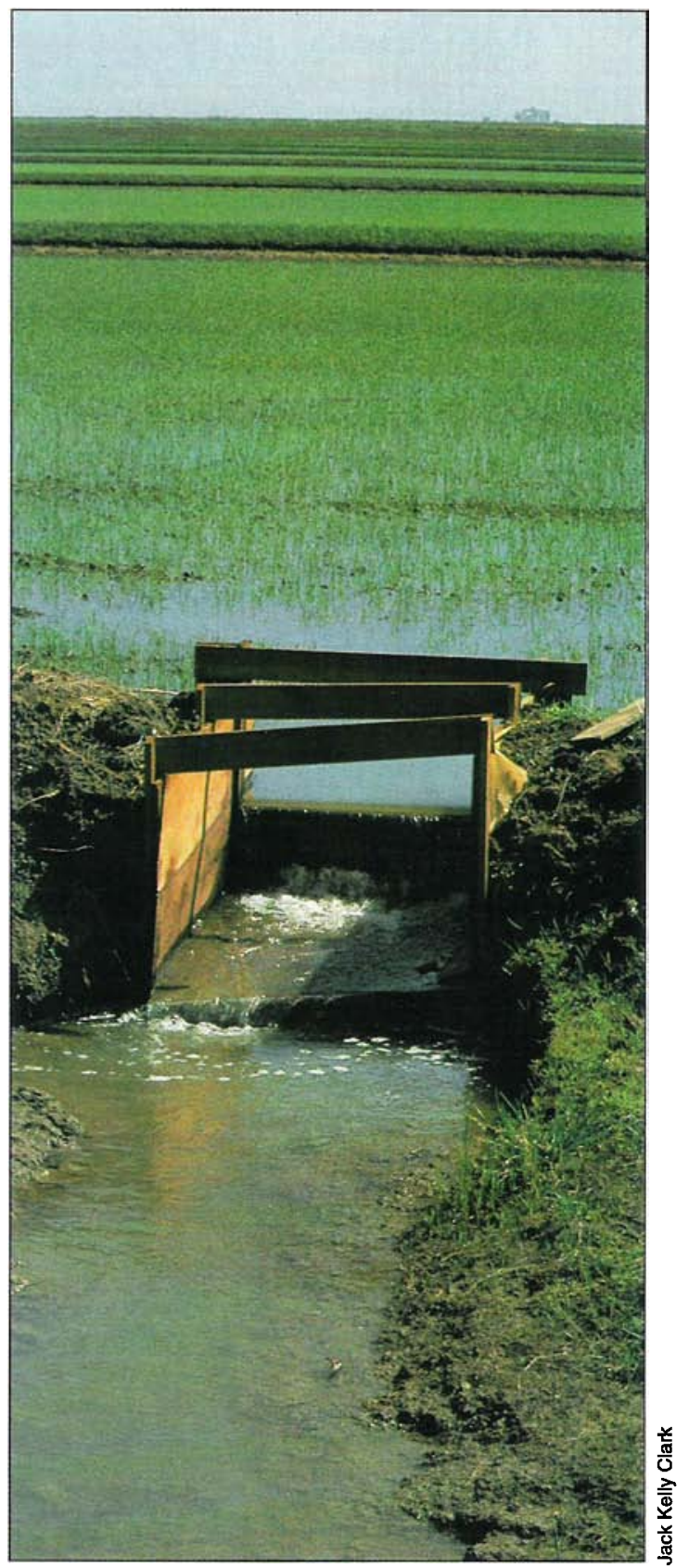

Water depth in a young rice field is controlled by rice boxes (weirs) with the goal of establishing a vigorous, weed-free crop stand.

ing and marketing expenses must continue to receive high priority within the industry and in the research activities of the University of California and other agencies. Accomplishing this task will be difficult under any circumstance, but doing so while addressing environmental concerns will test the ingenuity of the best of California's rice producers and their associates in the rice industry.

E. W. Learn is Professor Emeritus, Department of Agricultural Economics, and Executive Vice Chancellor Emeritus, UC Davis. 